\title{
A New Ground Power Unit (GPU) Supply for Aircraft Applications
}

\author{
M. Rivera ${ }^{\dagger 1}$, D. Faundez ${ }^{\dagger 2}$, J. Kolar*3 ${ }^{*}$ P. Wheeler ${ }^{\ddagger 4}$, F. Besoain ${ }^{\dagger 5}$ and J.A. Riveros ${ }^{\dagger 6}$ \\ ${ }^{\dagger}$ Faculty of Engineering, Universidad de Talca \\ Curico, CHILE \\ ${ }^{1}$ marcoriveutalca.cl \\ 2 dfaundez12@alumnos.utalca.cl \\ 5 fbesoaineutalca.cl \\ ${ }^{*}$ ETH Zurich \\ Zurich, SWITZERLAND \\ ${ }^{3}$ kolarelem.ee.ethz.ch \\ * The University of Nottingham \\ Nottingham, UK \\ ${ }^{4}$ Pat. Wheeler@nottingham.ac.uk
}

\begin{abstract}
Nowadays, electrical energy is the alternative to supply aircraft systems. In this paper a new converter for ground power units supply in aircraft applications is proposed. The topology consists of a rectifier with an active current injection circuit linked to a three level neutral point clamped converter. The design procedure is detailed in this paper showing the principal requirements for the safe operation of the converter. Simulation results validate the satisfying performance of the proposed system.
\end{abstract}

Resumen- Hoy en día, la energía eléctrica es la alternativa para suministrar sistemas de aviones. En este artículo se propone un nuevo convertidor para el suministro de unidades de potencia en tierra en aplicaciones de aviones. La topología consiste de un rectificador con un circuito de inyección de corriente activo conectado a un convertidor de tres niveles con enclavamiento del punto neutro. El procedimiento de diseño se detalla en este documento, mostrando los principales requisitos para la operación segura del convertidor. Resultados de simulación validan el buen desempeño del sistema propuesto.

\section{INTRODUCTION}

Currently it is preferable to use electrical energy to replace pneumatic, hydraulic and mechanical means to feed aircraft systems such as utility function, flight control actuation, and environmental control systems. This option presents the benefits of decreased weight of the aircraft, reduced necessity for support equipment in ground as well as maintenance and expanded reliability.

Ground power units (GPUs) are considered as power supply for aircrafts in military and civil aviation, ships, radar and others. The machinery is meant to be established in airports and employed as the electrical power supply for airplanes during refueling and loading operations. This is preferable with the goal of reducing costs, because the power can be converted on the ground in a cheap and efficient way than burning jet fuel on the airplane. The main application of this equipment is to turn off the auxiliary power unit (APU) of the airplane to decrease air contamination, noise, maintenance revision of the APU or inclusive engine starting.
The main challenges for these supply systems are:

- To provide $115[\mathrm{~V}]$ operating at $400[\mathrm{~Hz}]$ irrespective of the load.

- To minimize the impact of input current on the electrical system of the aircraft, they must be with reduced harmonic content.

- In order to minimize reactive power requirements a high input power factor must be accomplished.

- To maximize power density to reduce the weight and size.

At the beginning, ground power units used optimized modulation techniques which deleted or minimized the total harmonic distortion and therefore decreasing the size for output filters. As analyzed previously, various inverters operating at reduced switching frequency are included through certain transformers to produce an output voltage of 12 , 24 , or even 48 pulses. The control of these converters are complex, having a slow dynamic response to load steps. Nowadays to ensure the operation with highly nonlinear loads and unsymmetrical and/or single-phase loads requirements are mandatory issues to be accomplished.

In [1], [2] three different topologies (12-pulse rectifier, three-level two-level three-phase rectifier) have been compared for applications in future more electric aircraft. The comparison was done in terms of volume, weight, power density, switching losses and efficiency. This comparison showed that active system depicts the promising of an increment of the power density with higher switching frequency and/or reducing volume of passive devices, in particular, the three-level rectifier is considered as the most suitable solution.

To improve the performance of the equipment, several control techniques have been presented. Among them it is possible to find sliding mode control, selective harmonic control, dead-beat (DB) control, repetitive control, proportional-integral (PI), optimum state space control, proportional-resonant (PR) control, feed-forward control, among others [3]-[7].

In [8] the classical configuration for a GPU which is 
formed by an uncontrolled AC-DC converter with a controlled DC-AC converter is presented. Only simulation results are showed with a space vector modulation scheme for the inverter side. A dual-loop proportional-resonant (DLPR) method is presented in [7]. The technique has the advantage of restricting load disturbance with fast dynamic response.

In [9] a resonant controller is presented for the operation of a $400[\mathrm{~Hz}]$ ground power unit considering the computation delay to keep reduced THD of the output voltage. In [10] a new control strategy is introduced using resonant controllers for the operation in parallel of $400[\mathrm{~Hz}]$ converters in ground power units (GPUs) for aircrafts. Parallel operation is required when a single equipment cannot meet the power requirements. It is observed that the phase, frequency and amplitude of the output voltages in the inverters must be carefully controlled (specially when resonant controllers are used) because even a reduced phase difference among the parallel inverters could generate huge circulating current. The proposed control strategy retains the benefits of using resonant controllers and high power sharing performance even with small impedance [11]-[14]. In [15], an individual voltage-loop with harmonic controller is presented to get a better waveform of the output voltage for a three singlephase H-bridge inverter with a multi-limb output transformer with Y-Y connection. A digital control method is proposed in [16] to mitigate load disturbance maintaining low THD and compensating computational delay. The technique uses resonant controllers designed as IIR filters to remove 3rd, 5 th and 7th harmonics. All these papers include only the control for the inverter but the rectifier and transformer are not deeply discussed.

In [17] a single-phase AC-AC matrix converter (SPMC) is used to obtain a constant $100[\mathrm{~V}]-400[\mathrm{~Hz}]$ output waveform despite of the perturbations in the load or supply. Classical modulation schemes for this converter are sinusoidal pulse width modulation (SPWM) and equal pulse width modulation minimizing the harmonic distortion.

The design, as well as the control and implementation of a three-phase GPU for aircraft servicing is presented in [18], [19] using a three-phase matrix converter where an output $L C$ filter is considered at the output side. A four-leg matrix converter with an output $L C$ filter is proposed to be used as a $400[\mathrm{~Hz}]$ aircraft ground power unit (AGPU) in [20], [21]. A resonant controller and a single loop repetitive voltage controller are considered to regulate the converter in order to obtain a fixed load frequency and voltage independent of the load present on the aircraft grid using optimal Venturini and SVM techniques. One important issue that has not been considered in these papers, is that no isolation and EMI filter considerations are provided.

In this paper a new ground power unit for aircraft applications is proposed. A detailed description of the topology as well as the procedure design will be introduced in the following pages.

\section{Proposal of a New Aircraft Ground Power UNIT}

\section{A. General Description}

The new architecture is presented in Fig. 1. The proposed topology correspond to a three-phase AC-DC rectifier with an input active filter circuit. This rectifier is linked to a threelevel neutral-point-clamped (NPC) converter connected to an isolated transformer which generates the required 115[V] with $400[\mathrm{~Hz}]$.

The three-phase rectifier with input active filter circuit was first proposed in [22] which consists of two active networks.

The shaping network is implemented with a half-bridge inverter commutation at high switching frequency. In this network a current-mode control generates the third-harmonic current which is synchronized with the AC mains.

The injection network is formed by three bidirectional commutation devices working at low frequency and an inductor. Only one of them must be turned on at avery time, nonetheless a short overlap along the control signals is necessary to prevent over-voltages due to the inductive characteristic. With these switches, it is possible to select the path of the inductor current to be added to the respective phase, generating a sinusoidal source current with a reduction in the conduction losses. The negative output voltage terminal is linked to the mains via a diode of the lower half bridge of the diode rectifier. Thus, no common mode voltage is being generated with the switching. The third harmonic injection rectifier shows a low implementation effort but without a control of the output voltage which is directly determined by the diode bridge rectifier exhibiting a sixpulse waveform at each cycle.

\section{B. Modulation of the Rectifier with Input Active Filter}

The current injection circuit is modulated at low frequency, following the input voltages of the rectifier considering that the active current injection occurs at any time into only one network phase based on Table I. The bi-directional switches of the injection circuit connects the filter inductor to the input phase with the lowest absolute value, allowing the operation with low power and losses. The magnitude of this injection current is defined by the output power of the converter. When the input active filter is disabled, the input currents flow through the diode bridge only and they are highly distorted. When the input active filter is enabled, the inductor current $i_{L}$ is injected through the bi-directional switches, achieving sinusoidal input currents.

TABLE I

MOdUlATION OF THE CURRENT INJECTION CIRCUIT

\begin{tabular}{cccc} 
Sector & $S_{a}$ & $S_{b}$ & $S_{c}$ \\
\hline $0^{\circ}-60^{\circ}$ & 0 & 1 & 0 \\
$60^{\circ}-120^{\circ}$ & 1 & 0 & 0 \\
$120^{\circ}-180^{\circ}$ & 0 & 0 & 1 \\
$180^{\circ}-240^{\circ}$ & 0 & 1 & 0 \\
$240^{\circ}-300^{\circ}$ & 1 & 0 & 0 \\
$300^{\circ}-360^{\circ}$ & 0 & 1 & 0 \\
\hline \hline
\end{tabular}

The switches of the half-bridge operate at high switching frequency. They are connected at the other end of the inductor and are used for the control of the input active filter inductor current $i_{L}$. With this input active filter inductor current $i_{L}$, the source currents present a sinusoidal waveform and in phase with their respective source voltage. 


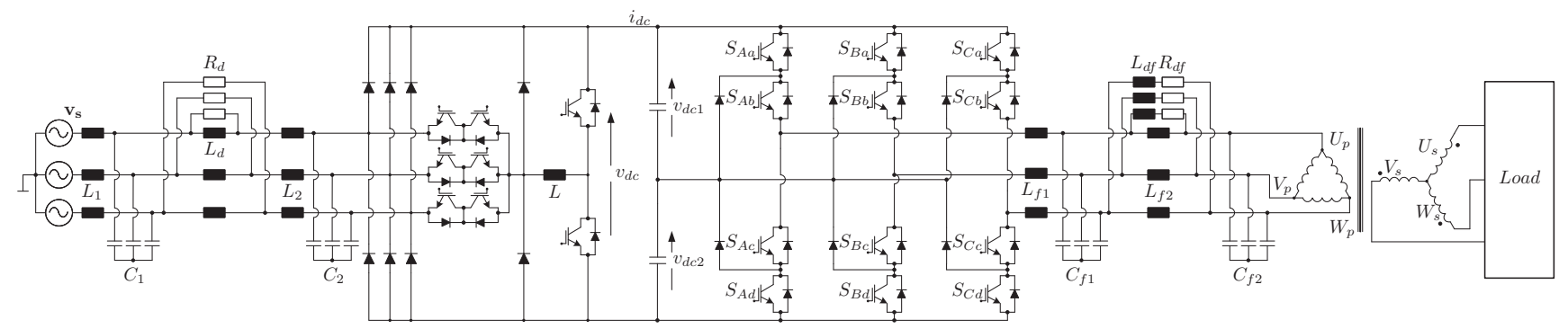

Fig. 1. Proposed topology for a new aircraft ground power unit

\section{Inductor Design}

The inductance value of the proposed converter is designed at the commutation frequency of the shaping network, considering:

$$
L \leq \frac{\sqrt{3} \times v_{a, r m s}}{4 \times f_{s} \times \Delta i}
$$

where $v_{a, r m s}$ is the voltage rms value, $f_{s}$ is the commutation frequency, and $\Delta i$ is the desired inductor current ripple.

By considering a $\Delta i=25 \%$ of the maximum current circulating through the inductor $i_{L y, \max }$, where $i_{L y, \max }=$ $I_{N} / 2$, with $I_{N}$ the amplitude of the input current $\left(I_{N}=\right.$ $\left.P / V_{N}\right)$.

For a power of $P=10[\mathrm{~kW}], V_{N}=480[\mathrm{~V}], \Delta i=$ 2.6[A] and a switching frequency $f_{s}=36[\mathrm{kHz}]$, the inductor value $L$ is given as

$$
L \leq \frac{\sqrt{3} \times 480}{4 \times 36000 \times 2.6} \leq 2.2[\mathrm{mH}]
$$

\section{Capacitor Design}

The capacitor $C$ is designed considering to limit the rise of the diode bridge output voltage. A reasonable margin is to establish the maximum voltage ripple $\Delta v$ around $2.5 \%$ of the diode bridge output voltage.

$$
C \leq \frac{I_{N}}{2 \times \Delta v \times f_{s}}\left(1-m_{\min }\right),
$$

with $m_{\min }$ the minimal modulation index.

In this work the maximum voltage ripple was selected as $\Delta v=1.5 \%$ of the diode bridge output voltage. Therefore,

$$
C \leq \frac{2.6}{2 \times(0.015 \times \sqrt{3} \times 480) \times f_{s}}(1-0.5) \leq 12[\mu F]
$$

By considering a series connection of the capacitors, it is obtained

$$
C=\frac{C_{1}+C_{2}}{C_{1} \times C_{2}}[\mu F]
$$

Assuming that $C_{1}=C_{2}$, thus

$$
C=\frac{C_{1}}{2}[\mu F]
$$

\section{E. Modulation for the NPC Inverter}

The output state considers a three-phase neutral-pointclamped (NPC) inverter with a delta-star isolation transformer. For simplicity, the NPC converter operates in an open loop. A compensation for the total DC-link voltage variation (six-pulse shape) is included in the modulation scheme.
It has been observed that there is no significative difference on the output side even when DC-link voltage presents large oscillations due to the injection of current $i_{m}$ through the mid-point of the capacitors (when no minimization of $i_{m}$ is considered). This effect produces large variations of voltage that reduce the operating range of the output voltage and can introduce low frequency harmonics.

The modulation of the inverter considers the minimization of the mid-point current $i_{m}$ in order to reduce these oscillations of the capacitor voltages in the DC-side.

\section{F. Output Filter Design}

The design of the output filter must accomplish the specifications regarding the quality of the output voltage waveform, dynamics and conducted electromagnetic interference (EMI). Based on Fig. 2, the following requirements have to be met:

- Peak-to-peak output voltage ripple $\Delta v_{\text {out }}$ bellow $1.0 \%$ of the nominal output voltage peak value, according to standard MIL-STD-704F. This is defined as $\Delta v_{\text {out }} \leq$ 4.6[V].

- Peak-to-peak filter inductor current ripple $\Delta i_{L}$ bellow $30 \%$ of the nominal output current peak value. For this case $\Delta i_{L} \leq 6.4[\mathrm{~A}]$.

- Maximum small signal output impedance $Z_{\text {out_max }}$. It is selected as 3.5 times higher maximum output impedance, $Z_{\text {out_max }} \leq 3.5[\Omega]$.

- Meet the standard according to MIL-STD-704F for conducted emission level.

- Additionally, the output filter should have minimum weight, minimum value, minimal cost and/or minimal losses.

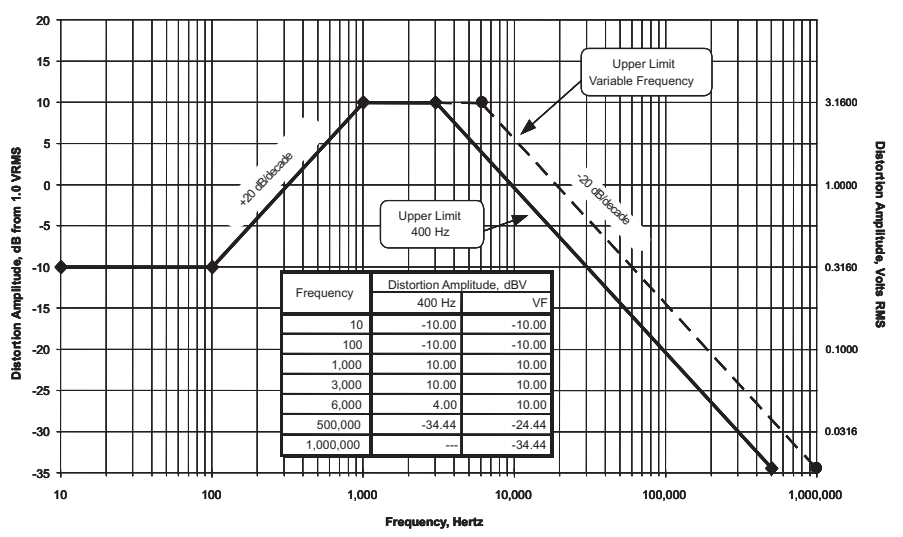

Fig. 2. Maximum distortion spectrum of $400[\mathrm{~Hz}]$ 
The design concept of the output filter, is to interpret the requirements previously mentioned into boundaries of the $L_{f}-C_{f}$ plane. Other restrictions like the maximum reactive filter capacitor current can be considered in the $L_{f}-C_{f}$ plane. By following the guidelines presented in [23], it is possible to obtain the optimal parameters for the filter and also to evaluate the promising advantages of several filter topologies (single-stage or multi-stage filters).

As demonstrated in [23], no design space exits in a singlestage output filter based on the mentioned requirements because the other requirements cannot be met at the same time EMI criterion. In order to solve this issue, there are at least four principal alternatives to define a common design space:

1) Diversified bridge-legs per phase could be operated interleaved and linked in parallel to a single-stage filter.

2) It is possible to increase the voltage level numbers to decrease the high frequency output voltage ripple.

3) Diversified bridge-legs per phase can be linked and operated hard in parallel to a single stage filter.

4) Output filter number stages can be increased to get higher attenuation for higher frequency components $(>150[\mathrm{kHz}])$ in the output voltage.

In order to save volume and cost, option 4 is selected by considering a two-stage output filter. $n$ and $k$ are scaling weights of the second filter stage which can be chosen to obtain the smallest total filter volume. Based on the analysis done in [23] (which was made using commercial information), the smallest filter volume is $V_{f, \min }=209.2 \mathrm{~cm}^{3}$ and it is obtained for $n=0.01$ and $k=0.9$. As depicted in Fig. 1, in order to avoid resonances produced at the second filter stage, a parallel $R_{d}-L_{d}$ damping filter is added. $L_{d}$ is selected as $L_{d}=n L_{f} / 2$.

The maximum ripple of the output voltage is given by eq. (7).

$$
\Delta v_{\text {out }}=\frac{m(1-m) v_{d c}}{16 L_{f} C_{f} f_{s}^{2}} \leq 4.6[V]
$$

where $m$ corresponds to the modulation index and $f_{s}$ is the switching frequency established as $f_{s}=36[\mathrm{kHz}]$. As observed, $\Delta v_{\text {out }}$ is equivalent to the DC-link voltage $v_{d c}$ and inversely equivalent to the commutation frequency.

The maximum ripple of the inductor current can be determined as:

$$
\Delta i_{L}=\frac{m(1-m) v_{d c}}{2 L_{f} f_{s}} \leq 6.4[A]
$$

It is observed that this expression does not depend on $C_{f}$, the filter capacitance value. The ripple of the current $\Delta i_{L}$ is equivalent to the DC-link voltage $v_{d c}$ and inversely equivalent to the commutation frequency.

The maximum output impedance is defined as:

$$
Z_{\text {out }}=\frac{L_{f}}{2(1-m) C_{f} Z_{\text {in }}} \leq 3.5[\Omega]
$$

where $Z_{\text {in }}=v_{d c} /\left(2 \Delta i_{\text {out }}\right)$. The output impedance is linear equivalent to the ratio along the filter inductance and the filter capacitance $L_{f} / C_{f}$.

In addition conducted emission are considered based on Fig. 2 where the maximum distortion spectrum of a 115[V] -
$400[\mathrm{~Hz}]$ system based on the standard MIL-STD-704F [24] is presented.

Finally, a maximum reactive filter capacitor current is considered where the peak value of the reactive current is defined by

$$
i_{c, \max }=w_{o} C_{f} \sqrt{2} v_{\text {out }, n} \leq 3[A]
$$

with $w_{o}=2 \pi 400$.

By using a commutation frequency of $f_{s}=36[\mathrm{kHz}]$, it is possible to obtain the following parameters that accomplish with the different design criterion:

- $L_{f 1}=574[\mu \mathrm{H}]$

- $C_{f 1}=3.58[\mu \mathrm{F}]$

- $L_{f 2}=5.74[\mu \mathrm{H}]$

- $C_{f 2}=3.22[\mu \mathrm{f}]$

- $L_{d}=2.87[\mu \mathrm{H}]$

The damping resistor $R_{d}$ is obtained based on [25]. The selection of $R_{d}$ that reduces the peak output impedance, for a given selection of $L_{d}$ is detailed by:

$$
R_{d}=R_{o} Q_{o p t}
$$

where

$$
\begin{gathered}
R_{o}=\sqrt{\frac{L_{f 2}}{C_{f 2}}} \\
Q_{o p t}=\sqrt{\frac{r(3+4 r)(1+2 r)}{2(1+4 r)}}
\end{gathered}
$$

with $r=L_{d} / L_{f 1}$. Thus $R_{d}=1.21 \Omega$.

\section{G. Isolation Transformer}

The output filter is connected to a delta-star isolation transformer. The reason behind the delta-star connection is because with this connection it is possible mitigate the effect of load imbalances and distortions.

$$
\begin{gathered}
\frac{N_{p}}{N_{s}}=a \\
V_{s}=\frac{\sqrt{3} v_{o}}{a}
\end{gathered}
$$

\section{Simulation Results}

In order to validate the performance of the proposed topology and the design of converter's components, simulations have been done in Gecko Simulation software. Three cases are considered: first when no input filter and no injection circuit are considered; second, when is evaluated the operation with an injection circuit and no input filter and finally, when both input filter and injection circuit are included.

Fig. 3 and Fig. 4 show the results for the first case. In Fig. 3 is evident that when no input filter and no injection circuit is considered, the source currents $i_{s A}$ are highly distorted which is an undesired effect (Fig. 3b). A good balance of the DC-link capacitors $v_{d c 1}$ and $v_{d c 2}$ is observed in Fig. $3 \mathrm{c}$. On the load side, the load current $i_{u}$ and load voltage $v_{u}$ show a sinusoidal waveform accomplished the desired voltage which has been established as $115[\mathrm{~V}]-400[\mathrm{~Hz}]$ (Fig. 4). 

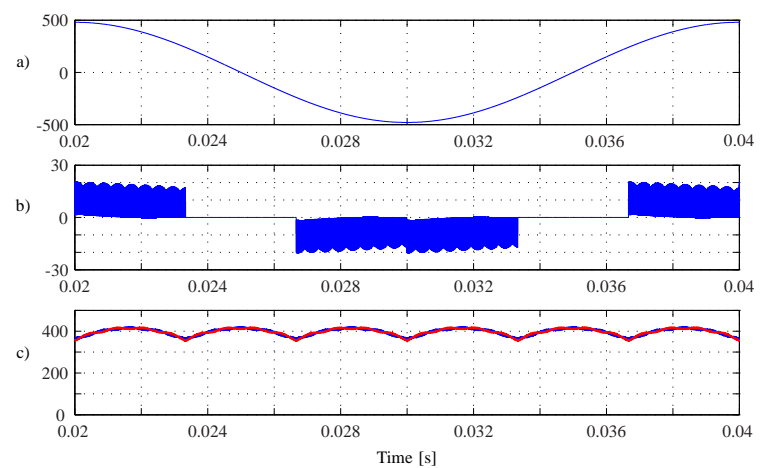

Fig. 3. Simulation results without input filter and injection circuit: a) source voltage $v_{s A}[\mathrm{~V}]$; b) source current $i_{s A}[\mathrm{~A}]$; c) capacitor voltages $v_{d c 1}[\mathrm{~V}], v_{d c 2}[\mathrm{~V}]$.
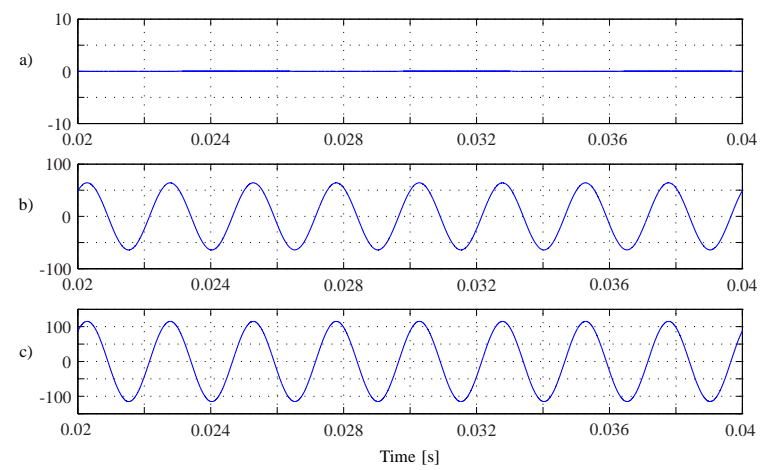

Fig. 4. Simulation results without input filter and injection circuit: a) IAF current $i_{L}[\mathrm{~A}]$; b) load current $i_{u}[\mathrm{~A}]$; c) load voltage $v_{u}[\mathrm{~V}]$.
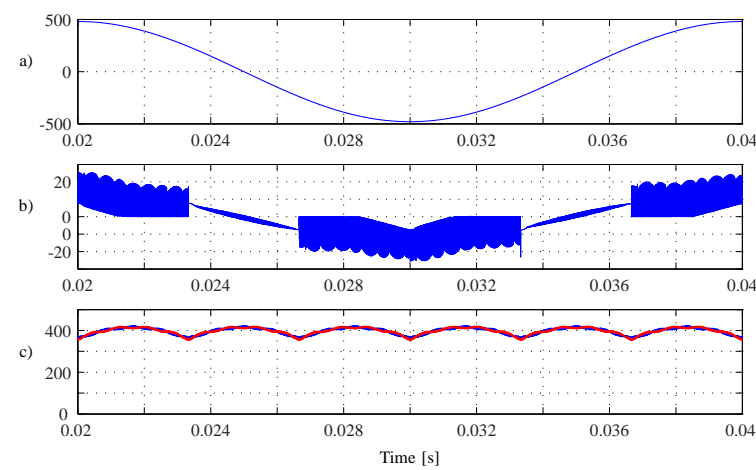

Fig. 5. Simulation results without input filter: a) source voltage $v_{s A}[\mathrm{~V}]$; b) source current $i_{s A}[\mathrm{~A}]$; c) capacitor voltages $v_{d c 1}[\mathrm{~V}], v_{d c 2}[\mathrm{~V}]$.
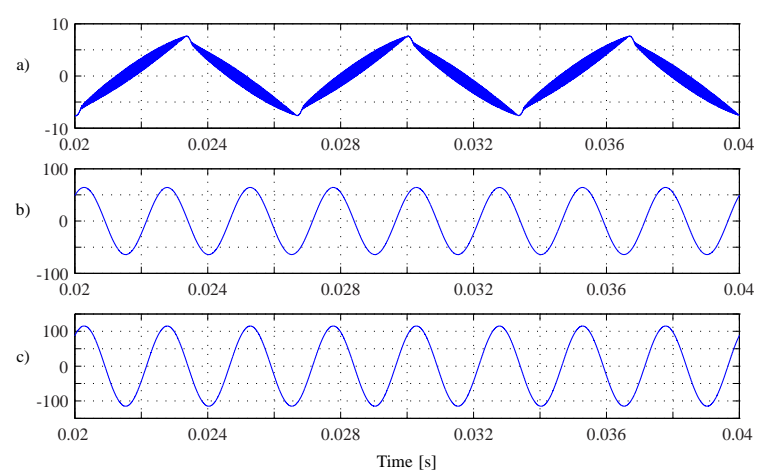

Fig. 6. Simulation results without input filter: a) IAF current $i_{L}[\mathrm{~A}]$; b) load current $i_{u}[\mathrm{~A}]$; c) load voltage $v_{u}[\mathrm{~V}]$.
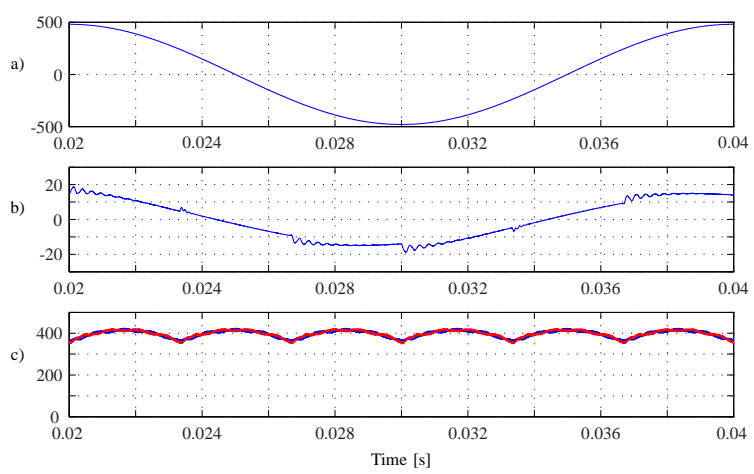

Fig. 7. Simulation results without input filter: a) source voltage $v_{s A}[\mathrm{~V}]$; b) source current $i_{s A}[\mathrm{~A}]$; c) capacitor voltages $v_{d c 1}[\mathrm{~V}], v_{d c 2}[\mathrm{~V}]$.
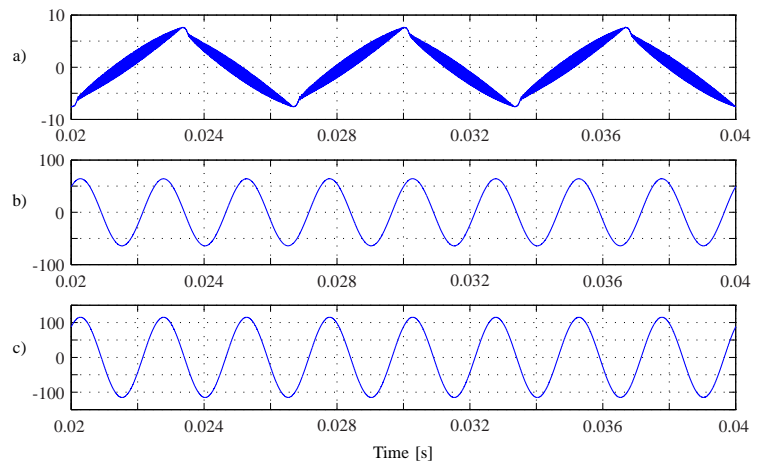

Fig. 8. Simulation results: a) IAF current $i_{L}[\mathrm{~A}]$; b) load current $i_{u}[\mathrm{~A}]$; c) load voltage $v_{u}[\mathrm{~V}]$.

The performance of the proposed converter when the injection circuit is considered but not an input filter, is depicted in Fig. 5 and Fig. 6. As expected the source current $i_{s A}$ presents a sinusoidal waveform but highly distorted (Fig. 5b). Similarly to the previous case, a good balance of the DC-link capacitors $v_{d c 1}$ and $v_{d c 2}$ is observed in Fig. 5c. An almost triangular waveform is obtained in the inductor current circulating through the injection circuit as indicated in Fig. 6a, which is necessary to impose a sinusoidal waveform at the input terminals. Again, the load current $i_{u}$ and load voltage $v_{u}$ show a sinusoidal waveform which accomplished the desired voltage which has been established as 115[V] - 400[Hz] (Fig. 6b and Fig. 6c).

Finally, Fig. 7 and Fig. 8 display the simulation results of the proposed converter, operating with the input filter and the injection current circuit. As expected, the performance of the proposed topology produces a sinusoidal source current $i_{s A}$ with a low harmonic distortion due to the injection circuit and the input filter. Similarly to the two previous cases, the DC-link capacitors $v_{d c 1}$ and $v_{d c 2}$ keep balanced all the time, Fig. 7c. In Fig. 8a is observed the inductor current through the injection circuit. Sinusoidal load current $i_{u}$ and voltage $v_{u}$ are observed Fig. 8 .

\section{CONCLUSION}

A new AC-AC topology for ground power unit supply in aircraft applications has been presented in this paper. The proposed converter is based in a AC-DC converter with an injection current circuit linked with a three-level neutral point clamp converter connected to an isolation transformer 
to generate $115[\mathrm{~V}]$ at $400[\mathrm{~Hz}]$. The design of the different components that create the converter are detailed. Simulation results have demonstrated the correct performance of the converter.

\section{ACKNOWLEDGMENT}

The authors would like to thank the financial support of FONDECYT Regular 1160690 and Postdoctoral 3170014 Research Projects as well as MEC Project 80150056.

\section{REFERENCES}

[1] G. Gong, M. Heldwein, U. Drofenik, K. Mino, and J. Kolar, "Comparative evaluation of three-phase high power factor ac-dc converter concepts for application in future more electric aircrafts," in Applied Power Electronics Conference and Exposition, 2004. APEC '04. Nineteenth Annual IEEE, vol. 2, 2004, pp. 1152-1159 vol.2.

[2] G. Gong, M. Heldwein, U. Drofenik, J. Minibock, K. Mino, and J. Kolar, "Comparative evaluation of three-phase high-power-factor ac-dc converter concepts for application in future more electric aircraft," Industrial Electronics, IEEE Transactions on, vol. 52, no. 3 , pp. 727-737, 2005.

[3] U. Jensen, M. Rasmussen, T. Mortensen, F. Blaabjerg, and J. Pedersen, "A new control method for $400 \mathrm{hz}$ ground power units for airplanes," in Industry Applications Conference, 1998. Thirty-Third IAS Annual Meeting. The 1998 IEEE, vol. 2, 1998, pp. 1469-1476 vol.2.

[4] U. Jensen, F. Blaabjerg, and J. Pedersen, "A new control method for 400-hz ground power units for airplanes," Industry Applications, IEEE Transactions on, vol. 36, no. 1, pp. 180-187, 2000.

[5] L. Mihalache, "Dsp control of $400 \mathrm{hz}$ inverters for aircraft applications," in Industry Applications Conference, 2002. 37th IAS Annual Meeting. Conference Record of the, vol. 3, 2002, pp. 1564-1571 vol.3.

[6] Z. Housheng, Z. Yanlei, and L. Haidong, "Design of three-phase intermediate frequency aviation power based on single chip microcomputer," in Computer Engineering and Technology (ICCET), 2010 2nd International Conference on, vol. 4, 2010, pp. V4-669-V4-672.

[7] J. Zhu, Z. Nie, W. Ma, and S. Nie, "Comparison between db control and dual-loop pr control for collapsed h-bridge single-phase $400 \mathrm{hz}$ power supply," in Industrial Electronics (ISIE), 2012 IEEE International Symposium on, 2012, pp. 240-245.

[8] G. Basile, S. Buso, S. Fasolo, P. Tenti, and P. Tomasin, "A 400 hz, $100 \mathrm{kva}$, digitally controlled ups for airport installations," in Industry Applications Conference, 2000. Conference Record of the 2000 IEEE, vol. 4, 2000, pp. 2261-2268 vol.4

[9] Z. Li, P. Wang, H. Zhu, Y. Li, L. Tan, Y. Chen, and F. Gao, "A new digital control method for high performance $400 \mathrm{hz}$ ground power unit," in Power Electronics and Motion Control Conference, 2008. EPE-PEMC 2008. 13th, 2008, pp. 515-520.

[10] F. Gao, P. Wang, Y. Li, Z. Li, and H. Zhu, "Wireless parallel operation of 400-hz high-power inverters in ground power units for airplanes," in Power Electronics and Motion Control Conference (EPE/PEMC), 2010 14th International, 2010, pp. T3-165-T3-171.

[11] Z. Li, Y. Li, P. Wang, H. Zhu, C. Liu, and F. Gao, "Single-loop digital control of high-power 400-hz ground power unit for airplanes," Industrial Electronics, IEEE Transactions on, vol. 57, no. 2, pp. 532543,2010

[12] L. Chun-xi, M. Wei-ming, S. Chi, and H. Wen-hua, "Research on harmonics suppression in high power middle frequency $400 \mathrm{hz}$ inverter," in Power and Energy Engineering Conference, 2009. APPEEC 2009. Asia-Pacific, 2009, pp. 1-4

[13] C. Liu, W. Ma, C. Sun, and W. Hu, "Research on digital control design of high power middle frequency $400 \mathrm{hz}$ inverter power," in Power Electronics and Motion Control Conference, 2009. IPEMC '09. IEEE 6th International, 2009, pp. 1544-1549.

[14] C. Liu, C. Sun, and W. Hu, "Proportional-resonant controller of high power $400 \mathrm{hz}$ inverter in stationary frame," in Electrical Machines and Systems, 2008. ICEMS 2008. International Conference on, 2008, pp. 1772-1777.

[15] H. Zhu, Y. Li, Z. Li, and P. Wang, "Design and performance analysis of high power static 400-hz supply," in Power and Energy Engineering Conference, 2009. APPEEC 2009. Asia-Pacific, 2009, pp. 1-4

[16] L. Mihalache, "Improved load disturbance rejection method for 400 hz gpu inverters," in Applied Power Electronics Conference and Exposition, 2004. APEC '04. Nineteenth Annual IEEE, vol. 1, 2004, pp. 95-101 Vol.1.
[17] G. Mahalakshmi, A. Jamna, and V. Jamuna, "A single phase matrix converter for agpu," in Computing, Electronics and Electrical Technologies (ICCEET), 2012 International Conference on, 2012, pp. 224-231.

[18] S. Lopez Arevalo, P. Zanchetta, P. Wheeler, A. Trentin, and L. Empringham, "Control and implementation of a matrix-converter-based ac ground power-supply unit for aircraft servicing," Industrial Electronics, IEEE Transactions on, vol. 57, no. 6, pp. 2076-2084, 2010.

[19] S. Arevalo, P. Zanchetta, and P. Wheeler, "Control of a matrix converter-based ac power supply for aircrafts under unbalanced conditions," in Industrial Electronics Society, 2007. IECON 2007. 33rd Annual Conference of the IEEE, 2007, pp. 1823-1828.

[20] W. Rohouma, L. Empringham, P. Zanchetta, and P. Wheeler, "A four legs matrix converter based ground power unit with selective harmonic control," in Energy Conversion Congress and Exposition (ECCE), 2011 IEEE, 2011, pp. 799-805.

[21] W. Rohouma, L. de Lillo, S. Lopez, P. Zanchetta, and P. Wheeler, "A single loop repetitive voltage controller for a four legs matrix converter ground power unit," in Power Electronics and Applications (EPE 2011), Proceedings of the 2011-14th European Conference on, 2011, pp. 1-9.

[22] N. Vazquez, H. Rodriguez, C. Hernandez, E. Rodriguez, and J. Arau, "Three-phase rectifier with active current injection and high efficiency," Industrial Electronics, IEEE Transactions on, vol. 56, no. 1, pp. 110-119, 2009.

[23] D. Boillat, T. Friedli, J. Muhlethaler, J. Kolar, and W. Hribernik, "Analysis of the design space of single-stage and two-stage lc output filters of switched-mode ac power sources," in Power and Energy Conference at Illinois (PECI), 2012 IEEE, Feb 2012, pp. 1-8.

[24] Y. Shanshui, L. Yan, Z. Jian, C. Mengdi, and W. Li, "Research on methods of distortion spectrum analysis for aircraft vfac power system," in Power Electronics and Applications (EPE), 2013 15th European Conference on, Sept 2013, pp. 1-8.

[25] R. Erickson, "Optimal single resistors damping of input filters," in Applied Power Electronics Conference and Exposition, 1999. APEC '99. Fourteenth Annual, vol. 2, Mar 1999, pp. 1073-1079 vol.2. 